\title{
Magnitude of reward and the frustration effect in a within-subjects design'
}

\author{
Riehard H. Peckham Jr. and Abram Amsel \\ UNIVERSITY OF TORONTO
}

\begin{abstract}
The effect of reward magnitude in the first goal box $\left(G_{1}\right)$ of a double runway on the size of the frustration effect (FE) was stuaied, using a within-subjects design. During a preliminary phase, 11 rats were run in black and in white first alleys $\left(A_{1}\right)$ the reward in $G_{1}$ being (say) large when $A_{1}$ was black and small when $A_{1}$ was white. Test trials followed, in which percent reward in $\mathrm{G}_{1}$ was reduced from 100 to 50 in both the large- and small-magnitude alleys. The results indicated a significantly larger $\mathrm{FE}$ after nonreward in the $\mathrm{A}_{1}$ associated with the larger reward. More important, N-trials following nonreward in the large-reward $A_{1}$ were significantly faster than $\mathrm{N}$-trials following nonreward in the small-reward $A_{1}$.
\end{abstract}

Problem

Theory of frustrative nonreward (Amsel, 1958, 1962; Spence, 1960) assumes a positive relationship between strength of the anticipatory reward response $\left(r_{R}\right)$ and frustration $\left(R_{F}\right)$. An indicant of $R_{f}$ is the frustration effect (FE), greater vigor of responding following nonreward than following reward, typically studied in the double-runway apparatus. Experiments (Roussel, 1952; Amsel \& Hancock, 1957), showing the gradual development of the $\mathrm{FE}$ when there is $50 \%$ reward in $\mathrm{G}_{1}$ from the outset of training as opposed to immediate and strong FE when there has been a previous prolonged period of continuous reward, are taken to support the hypothesized relationship between $r_{R}$ and $R_{F}$. Experiments showing a positive relationship between size of the $\mathrm{FE}$ and the similarity of $\mathrm{G}_{1}$ to $\mathrm{A}_{1}$ (Amsel \& Hancock, 1957; Amsel et al., 1960) have also been offered as support for this relationship, as has the finding that length of $\mathrm{A}_{1}$ and magnitude of the $\mathrm{FE}$ measured in $\mathrm{A}_{2}$ are positively related (Amsel et al., 1960). To date, there has been no direct experimental demonstration of a relationship between magnitude of reward in $\mathrm{G}_{1}$ and the FE. The closest thing to such a demonstration is an experiment by Bower (1962), which showed that the FE can be obtained with reduced reward as well as nonreward. However, no information is provided regarding effects of size of reward in $G_{1}$ on the $F E$ when different magnitudes of $G_{1}$ are reduced to zero. The present study was designed to test the hypothesis that magnitude of the $\mathrm{FE}$ is directly related to magnitude of reward in $G_{1}$, using a within-subjects design.

\section{Method}

Six female and five male hooded rats, approximately 130 days old, served as Ss. The apparatus consisted of two straight, parallel double runways. It contained the following sections: a pre-start box (PSB); start box (SB); two parallel first alleys, one white $\left(A_{1} W\right)$, the other black $\left(\mathrm{A}_{1} \mathrm{~B}\right)$; and two corresponding parallel goal sections $\left(G_{1} W\right.$ and $\left.G_{1} B\right)$; two second alleys $\left(A_{2}\right)$, each of which was painted grey, and two corresponding goal sections $\left(G_{2}\right)$ also painted grey and identical in all details. Both first alleys and both second alleys were mounted as a single unit on rollers and could be moved laterally so that either the black or white side was aligned with the PSB and SB sections. Food cups were placed at the end and on the left side of each of the four goal boxes. The doors were of the guillotine type, and were raised and lowered by means of a system of pulleys suspended above the runways. A timing system consisting of photocells and timers was used to record $A_{1}$ starting, running and goal times in successive 12-in segments of $A_{1}$. Starting and running times were similarly taken from successive 12-in segments of $A_{2}$. All Ss were maintained at $80 \%$ of their original body weight, and given preliminary acquisition training four trials per day for 64 days. A large magnitude of reward (8 $37-\mathrm{mg}$ Noyes pellets) was presented in $G_{1}$ on two of the four trials each day and a small magnitude of reward ( 2 pellets) was presented $\mathrm{G}_{1}$ on the other two trials. For any given $S$, each magnitude was presented consistently with either the black of the white $A_{1}$, thus enabling them to learn a black-white discrimination on the basis of differential magnitude of reward. All Ss received 2 pellets in $\mathrm{A}_{2}$ consistently throughout acquisition and test trials. To control for possible reaction to $A_{1}$ brightness, half the $S$ s received 8 pellets in $G_{1}$ when $A_{1}$ was black, and 2 pellets in $G_{1}$ when $A_{1}$ was white (Group 8B-2W); in the other group $(8 \mathrm{~W}-2 \mathrm{~B})$ the relationships were reversed. Order of presentation of 2- and 8-pellet trials was determined by the following four kinds of daily trial sequences: $R_{8} R_{2} R_{8} R_{2}, R_{2} R_{2} R_{8} R_{8}, R_{2} R_{8} R_{2} R_{8}$, and $R_{8} R_{8} R_{2} R_{2}$. Each $S$ was assigned a repeating combination of these four sequences in a pseudo-random fashion.

Test trials were run for 12 days and were identical to the acquisition trials, except that percent $\mathrm{G}_{1}$ reward on each of the two kinds of trials was changed from 100 to 50 as follows: On alternating days, the first and last trials or middle two trials, respectively, were designated nonreward (N) trials. The ordinary FE test trial procedure (Amsel \& Roussel, 1952) was thereby conducted separately in relation to each of the two color cues within the same $\mathrm{S}$. 


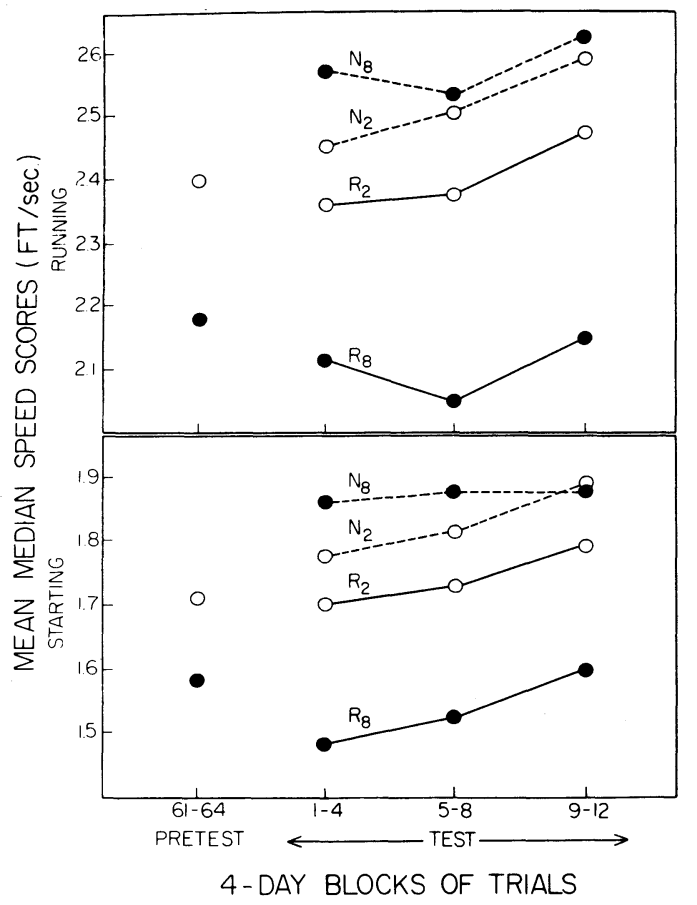

Fig. 1 .

\section{Hesults}

All of the test trial data for any measure involve only within-S comparisons. $A_{2}$ starting and running speeds (1/time) are presented graphically in Fig. 1 . The general pattern of the results seems the same with both measures. Each point on the graph represents the mean of 11 individual-S medians over a 4-dayblock for one of the four types of test trial. A S's score for each of the four kinds of trial was determined by taking the mean of the three 4-day block medians. Data for the two color groups have been combined, since there was little difference between them in $\mathrm{A}_{2}$ measures during test trials. The statistical analyses presented below in relation to the three kinds of comparison were performed on the data from the starting measure.

The $N$ minus $R$ differences (FE). Speeds are faster in $A_{2}$ after nonreward in $G_{1}$ than after reward in $\mathrm{G}_{1}$ both in the large magnitude alley $\left(\mathrm{N}_{8}\right.$ minus $\left.\mathrm{R}_{8}\right)$ and in the small magnitude alley $\left(\mathrm{N}_{2}\right.$ minus $\left.\mathrm{R}_{2}\right)$. Eight of 11 Ss showed positive $N_{8}$ minus $R_{8}$ differences, and a paired observation analysis of these differences was statistically significant ( $t, 4.89 ; \mathrm{df}, 10 ; \mathrm{p}<.0005)$. Nine of 11 Ss showed positive $\mathrm{N}_{2}$ minus $\mathrm{R}_{2}$ differences, and a paired observation analysis of these differences was also significant ( $t, 3.00 ; \mathrm{df}, 10 ; \mathrm{p}<.01)$.

Comparison of 8 -pellet and 2-pellet FEs. It is clear, graphically, that the $\mathrm{N}_{8}$ minus $\mathrm{R}_{8}$ difference (FE to 8 pellets) is larger than the $\mathrm{N}_{2}$ minus $\mathrm{R}_{2}$ differences (FE to 2 pellets). Ten of $11 \mathrm{Ss}$ showed positive $\mathrm{FE}_{8}$ minus $\mathrm{FE}_{2}$ differences; and a paired observation analysis of these differences was statistically significant ( $t, 4.95 ; \mathrm{df}, 10 ; \mathrm{p}<.0005)$.

Comparison of $\mathrm{N}_{8}$ and $\mathrm{N}_{2}$ trials. There is a small but consistent difference between the $\mathrm{N}_{8}$ and $\mathrm{N}_{2}$ trials for both the starting and running measures. Positive $\mathrm{N}_{8}$ minus $\mathrm{N}_{2}$ differences were observed in 9 of the $11 \mathrm{Ss}$, and a paired observations analysis of these differences was significant ( $t, 2.34 ; \mathrm{df}, 10 ; p<.025)$. In the view of the pretest and test performance of Ss on $R_{8}$ and $R_{2}$ trials, $R_{2}$ speeds being always much faster than $R_{8}$ speeds, this significant inversion of performance levels on $\mathrm{N}_{8}$ and $\mathrm{N}_{2}$ test trials seems particularly noteworthy.

\section{Diseussion}

Despite the fact that $\mathrm{Ss}$ run more slowly in $\mathrm{A}_{2}$ during preliminary and test trials after 8 pellets in $G_{1}$ than after 2 pellets, they run faster in $A_{2}$ after nonreward to the 8-pellet cue than they do to the 2-pellet cue. This striking reversal, within-subjects, provides evidence for an hypothesis relating the FE to magnitude of reward that is entirely free of the "demotivation hypothesis" objection (Seward et al., 1957). Apart from difference in color of $\mathrm{A}_{1}$, the $\mathrm{N}_{8}$ and $\mathrm{N}_{2}$ trials are identical operationally, and yield a difference within Ss which can be understood only associatively: the $\mathrm{N}_{8}$ trials occur in the presence of a stimulus signalling 8 pellets and the $\mathrm{N}_{2}$ trials occur when the other stimulus signals 2 pellets. Presumably, two discriminable stimuli conditioned to two magnitudes of a goal can control, within the same organism, two different strengths of $r_{R}$, each in turn producing its own appropriate value of $R_{F}$ when reward is withheld.

\section{References}

AMSEL, A. The role of frustrative nonreward in noncontinuous reward situations. Psychol. Bull., 1958, 55, 102-119.

AMSEL, A. Frustrative nonreward in partial reinforcement and discrimination learning: some recent history and a theoretical extension. Psychol. Rev., 1962, 69, 306-328.

AMSEL, A., ERNHART, C. B., \& GALBRECHT, C. R. Magnitude of frustration effect and strength of antedating goal factors. Psychol. Rep., 1961, 8, 183-186.

AMSEL, A., \& HANCOCK, W. Motivational properties of frustration: III. Relation of frustration effect to antedating goal factors. J. exp. Psychol., 1957, 53, 126-131.

AMSEL, A., \& ROUSSEL, J. Motivational properties of frustration: I. Effect on a running response of the addition of frustration to the motivational complex. J. exp. Psychol., 1952, 43, 363-368.

BOWER, G. H. The influence of graded reductions in reward and prior frustrating events upon the magnitude of the frustration effect. J. comp. physiol. Psychol., 1962, 55, 582-587.

ROUSSEL, J. Frustration effects as a function of repeated non-reinforcements and as a function of the consistency of reinforcement prior to introduction of non-reinforcement. Unpublished master's thesis, Tulane University, 1952.

SEWARD, J. P., PEREBOOM, A. C., BUTLER, B., \& JONES, R. B. The role of prefeeding in apparent.frustration effect. J. exp. Psychol., $1957,54,445-450$.

SPENCE, K. W. Behavioral theory and learning. Englewood Cliffs: Prentice-Hall, 1960.

Note

1. Supported by a grant (GB-143) from the National Science Foundation. 